ORIGINAL ARTICLE

\title{
Crisis management during regional anaesthesia
}

\author{
M A L Fox, R W Morris, W B Runciman, A D Paix
}

Qual Saf Health Care 2005;14:e24 (http://www.qshc.com/cgi/content/full/14/3/e24). doi: 10.1136/qshc.2002.004382

Background: Regional anaesthesia is widely used and has been considered to pose few risks once the block is established. However, life threatening problems can occur both during the establishment and maintenance phases of a regional block which require prompt recognition and management.

Objectives: To examine the role of a previously described core algorithm "COVER ABCD-A SWIFT CHECK", supplemented by a specific sub-algorithm for regional anaesthesia, in the management of problems arising in association with regional anaesthesia.

Methods: The potential performance of this structured approach was assessed for each of the relevant incidents among the first 4000 reported to the Australian Incident Monitoring Study (AIMS).

See end of article for authors' affiliations Results: There were 252 incidents involving regional anaesthesia, $6.3 \%$ of the first 4000 reports to AIMS. Of these, the majority (78\%) involved the use of epidural or spinal anaesthesia. The core algorithm $A B$ COVER CD properly applied, would have accounted for $45 \%$ of all problems, and is worth applying to eliminate unexpected problems unrelated to the regional anaesthesia technique itself. Hypotension and dysrhythmias made up over $30 \%$ of all incidents and accounted for all six deaths in the 252 incidents. The specific sub-algorithm for regional anaesthetic techniques accounted for $55 \%$ of all incidents: problems with delivery to the site of action, 49 cases (19\%); problems with the block, 30 cases (12\%); local anaesthetic toxicity, 30 cases (12\%); trauma, infection, or pain, 14 cases $(6 \%)$, wrong side or wrong patient, five cases (2\%).

Correspondence to: Professor W B Runciman President, Australian Patient Safety Foundation, GPO Box 400, Adelaide, South Australia, 5001, Australia; research@ apsf.net.au

Accepted 12 January 2005 Conclusion: Based on an analysis of 252 incidents, the core algorithm and the regional anaesthesia subalgorithm, properly applied, would lead to swift recognition and appropriate management of problems arising in association with regional anaesthesia.

$\mathrm{R}$ egional anaesthesia is widely used and has been considered by some to pose few risks once the block is established. However, in addition to the risks posed by local anaesthetic toxicity ${ }^{2}$ and misplaced or misdirected needles and cannulae, a variety of other problems may occur, both during and after blockade. ${ }^{3-5}$ Some of these may be obscure and not related to the regional anaesthetic procedure itself. As problems need to be promptly recognised and managed, it was decided to examine the role of a structured approach to such problems arising in association with regional anaesthesia.

In 1993, a "core" crisis management algorithm, represented by the mnemonic COVER ABCD-A SWIFT CHECK (the AB precedes COVER for the non-intubated patient), was proposed as the basis for a systematic approach to any crisis during anaesthesia where it is not immediately obvious what should be done, or where actions taken have failed to remedy the situation. ${ }^{6}$ This was validated against the first 2000 incidents reported to the original Australian Incident Monitoring Study (AIMS). AIMS is an ongoing study which involves the voluntary, anonymous reporting of any unintended incident which reduced, or could have reduced, the safety margin for a patient. ${ }^{7}$

It was concluded that if this algorithm had been correctly applied, a functional diagnosis would have been reached within 40-60 seconds in 99\% of applicable incidents, and the learned sequence of actions recommended by the COVER portion would have led to appropriate steps being taken to handle the $60 \%$ of problems relevant to this portion of the algorithm. ${ }^{6}$ However, this study also showed that the $40 \%$ of problems represented by the remainder of the algorithm, ABCD-A SWIFT CHECK, were not always promptly diagnosed or appropriately managed. ${ }^{6-8}$ It was decided that it would be useful, for these remaining problems, to develop a set of sub-algorithms in an easy to use crisis management

manual. ${ }^{9}$ This study reports on the place of the COVER ABCD-A SWIFT CHECK algorithm in the diagnosis and initial management of problems arising in association with regional anaesthesia, provides an outline of a specific crisis management sub-algorithm for these problems, and provides an indication of the potential value of using this structured approach.

\section{METHODS}

Of the first 4000 incidents reported to AIMS, those which made reference to regional anaesthesia alone were extracted and analysed for operative procedure, regional anaesthetic technique, type of event, ASA status, timing of events, physiological effects, and outcome. The COVER ABCD-A SWIFT CHECK algorithm, described elsewhere in this set of articles, ${ }^{9}$ was applied to each relevant report to determine the stages at which the problem might have been diagnosed and to confirm that activating the COVER portion would have led to appropriate management steps being taken. It should be

Table 1 Regional anaesthesia techniques

\begin{tabular}{lcr}
\hline Regional anaesthesia techniques & Number of reports & $\%$ \\
\hline Epidural & 98 & 39 \\
Spinal & 91 & 36 \\
Ophthalmic block & 23 & 9 \\
Brachial plexus block & 21 & 8 \\
Combined spinal/epidural & 4 & 2 \\
Bier's block & 5 & 2 \\
Caudal & 3 & 1 \\
Cervical plexus block & 3 & 1 \\
Other & 5 & 2 \\
Total & 252 & 100 \\
\hline
\end{tabular}




\section{REGIONAL ANAESTHESIA 1 EPIDURAL/SPINAL}

\section{EMERGENCY MANAGEMENT}

Question the patient, reassure, and sedate if appropriate. Inform the surgeon as to the nature of the problem.

Complete AB COVER CD-A SWIFT CHECK.

If hypotensive $\rightarrow$ page $32^{*}(1)^{* *}$

If bradycardic $\rightarrow$ page $28^{*}(1)^{* *}$

Do not hesitate to treat as cardiac arrest $\rightarrow$ page $38^{*}(1)^{* *}$

Review and treat probable causes: (2)**.

Inadequate fluid loading, blood loss.

High block (aspirate CSF from epidural?)

Drug errors - Wrong drug, concentration or volume

- Wrong site

- Incorrect infusion rate.

Ensure: fluid, drug and infusion rates are correct.

For suspected local anaesthetic toxicity (3)**

Give phenytoin $15 \mathrm{mg} / \mathrm{kg}$ over 30 minutes for CNS irritability. Control seizures with $50-100 \mathrm{mg}$ of thiopentone but beware of cardiovascular compromise.

For cardiovascular collapse, treat as cardiac arrest $\rightarrow$ page $38^{*}$.

\section{Assess the block $(2,4,5)^{* *}$}

If inadequate consider general anaesthesia, local infiltration or further local anaesthetic down the epidural catheter (2)(4)**.

If excessive, administer oxygen and assist ventilation if required (3) $(5)^{* *}$.

Consider needle/catheter problem (6) **

Wrong site - Inadvertent intravascular placement/injection.

- Inadvertent intrathecal placement/injection.

- Inadvertent intrapleural placement/injection.

Trauma - Haematoma.

- Nerve damage.

- Pneumothorax.

- Pain.

Beware tourniquet failure with Bier's blocks.

This forms a facing page of the Crisis Management Manual 10 .

* Page references refer to Crisis Management Manual 10 .

** Numbers in brackets refer to Notes in the right hand panel.

\section{FURTHER CARE}

Confirm and correct cause

Review patient to determine delayed events (5)(6)

Counsel the patient, arrange follow up

\section{NOTES:}

There were 252 reports of incidents involving regional anaesthesia reported to AIMS. Of these $78 \%$ were either epidural or spinal anaesthesia related.

(1) Hypotension and arrhythmia in spinal/epidural incidents reported accounted for $30 \%$ of all regional anaesthesia incidents, and the deaths in $2 \%$. They involved a combination of high block and or hypovolaemia.

(2) Common precipitants included:

Inadequate time for assessment

Elderly patients with multiple medical problems

Usual dosages of local anaesthetics having a more profound effect in the elderly.

Error in judgement of level of block and or blood loss.

(3) Local anaesthetic toxicity was reported in $10 \%$ of all cases with fitting in one third of these.

(4) Failed blocks $-5 \%$ of all regional anaesthesia incidents.

(5) Overdose/total spinal $-10 \%$ of all regional anaesthesia incidents. Most common problems cited included:

Dural puncture $-13 \%$ of all reports.

Post dural puncture headache $-52 \%$ of dural punctures, with $75 \%$ of these requiring a blood patch.

Miscellaneous problems of epidurals: abscess, hematoma, subarachnoid migration, and prolonged recovery.

(6) Trauma, infection or pain was reported in $6 \%$ of cases.

These notes comprise a reverse side of a page of the Crisis Management Manual ${ }^{10}$.

Figure 1 Regional anaesthesia 1 epidural/spinal.

noted that for a patient breathing spontaneously, A and B precede COVER (that is, the sequence is AB COVER CD) and, for a patient breathing spontaneously and receiving oxygen

Table 2 Type of surgical specialty in which regional anaesthesia incidents occurred

\begin{tabular}{lcc}
\hline Type of surgical specialty & Number of incidents & $\%$ \\
\hline Obstetrics & 65 & 26 \\
Orthopaedics & 46 & 18 \\
Urology & 40 & 16 \\
Vascular surgery & 29 & 12 \\
General surgery & 27 & 11 \\
Ophthalmology & 23 & 9 \\
Plastic surgery & 10 & 4 \\
Gynaecology & 4 & 2 \\
Not stated & 3 & 1 \\
Chronic pain & 3 & 1 \\
Paediatric general surgery & 1 & $<1$ \\
Cardiothoracic surgery & 1 & $<1$ \\
Total & 252 & 100 \\
\hline
\end{tabular}

from a source independent of an anaesthetic machine, the $\mathrm{O}$ refers to systematically checking the oxygen supply from the wall outlet to the mask or other device delivering oxygen to the patient; additionally, the $\mathrm{V}$ and $\mathrm{E}$ of COVER become redundant. Also, if the patient is awake or rousable, the first step is to "ask the patient".

As problems specific to regional anaesthesia are not adequately dealt with by this core algorithm, a specific subalgorithm for these problems was developed (see fig l) and

Table 3 The ASA status of the patients involved in the regional anaesthesia incidents

\begin{tabular}{lcr}
\hline ASA status & Number of incidents & $\%$ \\
\hline ASA I & 73 & 29 \\
ASA II & 75 & 30 \\
ASA III & 83 & 33 \\
ASA IV & 15 & 6 \\
ASA Unknown & 6 & 2 \\
Total & 252 & 100 \\
\hline
\end{tabular}


Table 4 Time of occurrence of regional anaesthetic incidents

\begin{tabular}{lcc}
\hline Time & Number of incidents & $\%$ \\
\hline Pre-induction & 1 & $<1$ \\
Establishment & 102 & 40 \\
Maintenance & 106 & 42 \\
Recovery & 16 & 6 \\
Post-recovery & 27 & 11 \\
Total & 252 & 100 \\
\hline
\end{tabular}

Table 5 Physiological outcome following regional anaesthesia incidents

\begin{tabular}{lcr}
\hline Outcomes & Number of incidents & \multicolumn{1}{l}{$\%$} \\
\hline No physiological change & 54 & 21 \\
Minor physiological change & 97 & 39 \\
Major physiological change & 95 & 38 \\
Death & 6 & 2 \\
Total & 252 & 100 \\
\hline
\end{tabular}

Table 6 AB COVER CD algorithm

\begin{tabular}{|c|c|c|c|c|c|}
\hline & \multirow[b]{2}{*}{ Description } & & \multicolumn{3}{|c|}{ Number } \\
\hline & & & $\mathrm{E} / \mathrm{S}^{*}$ & $\mathrm{BrPl}+$ & Oph \\
\hline A & & - & - & - \\
\hline \multirow[t]{3}{*}{ B } & \multicolumn{2}{|l|}{ Breathing ( 3 cases) } & & & \\
\hline & \multicolumn{2}{|c|}{ Apnoea during LSCS (1), delayed respiratory depression (1) } & 2 & - & - \\
\hline & \multicolumn{2}{|c|}{ Laryngeal nerve palsy } & - & 1 & - \\
\hline \multirow[t]{4}{*}{ C } & \multirow{2}{*}{\multicolumn{2}{|c|}{$\begin{array}{l}\text { Circulation (pulse) } \\
\text { Although some of the cases of hypotension and dysrhythmia may } \\
\text { have been detected by feeling the pulse volume, these are included } \\
\text { at the } C \text { stage of } C D \text { in the algorithm as they would be detected } \\
\text { during the systematic check of the circulation (see Circulation, below) } \\
\text { Colour ( } 4 \text { cases) }\end{array}$}} & - & - & - \\
\hline & & & & & \\
\hline & \multirow{2}{*}{\multicolumn{2}{|c|}{$\begin{array}{l}\text { Colour ( } 4 \text { cases) } \\
\text { Hypoxia during sedation } \\
\text { Hypoxia during positioning }\end{array}$}} & 2 & - & 1 \\
\hline & & & $\overline{1}$ & - & - \\
\hline \multirow[t]{2}{*}{ O } & \multicolumn{2}{|c|}{ Oxygen supply to patient } & - & - & - \\
\hline & \multicolumn{2}{|l|}{ Oxygen analyser } & - & - & - \\
\hline \multirow[t]{4}{*}{ V } & \multicolumn{2}{|l|}{ Ventilation } & - & - & - \\
\hline & \multicolumn{5}{|l|}{ Vaporisors (4 cases) } \\
\hline & Vaporiser left on & & 2 & 1 & - \\
\hline & \multicolumn{2}{|l|}{ Overfilled vaporiser } & 1 & - & - \\
\hline \multirow[t]{2}{*}{$E$} & \multicolumn{2}{|l|}{$\begin{array}{l}\text { Endotracheal tube } \\
\text { Eliminate }\end{array}$} & - & - & - \\
\hline & Eliminate & & - & - & - \\
\hline $\mathrm{R}$ & \multicolumn{5}{|l|}{ Review monitors ( 8 cases) } \\
\hline & $\begin{array}{l}\text { Blood pressure measur } \\
\text { not turned on (1); failu }\end{array}$ & $\begin{array}{l}\text { appropriate cuff application (1); } \\
\text { asure (1); erroneous reading (1) }\end{array}$ & 4 & - & - \\
\hline & Capnograph: $\mathrm{CO}_{2}$ wa & nissing & 1 & - & - \\
\hline & Electrocardiogram: inc & & 1 & - & - \\
\hline & No foetal heart monito & & 1 & - & - \\
\hline & Hypothermia & & 1 & - & - \\
\hline & Review equipment ( 8 cas & & 1 & - & - \\
\hline & Intravascular air & & 1 & - & - \\
\hline & Surgeon punctured intr & line & 1 & - & - \\
\hline & Leaking Haemaccel fla & & 1 & - & - \\
\hline & No IV access - forgott & & 1 & - & - \\
\hline & Burn via diathermy & & 1 & - & - \\
\hline & Drug fridge turned off & & 1 & - & - \\
\hline & Wrong table & & 1 & - & - \\
\hline & Fell off table & & - & - & 1 \\
\hline $\mathrm{C}$ & Circulation (60 cases) & & & & \\
\hline & $\begin{array}{l}\text { Hypotension ( } 25 \text { spina } \\
\text { epidural cases includin }\end{array}$ & $\begin{array}{l}\text { cluding } 4 \text { deaths, } 10 \\
\text { hs } 1 \text { brachial plexus case) }\end{array}$ & 35 & 1 & - \\
\hline & Bradycardia (7 spinal, & almic cases) & 7 & - & 5 \\
\hline & Hypertension (3 spinal & & 3 & - & - \\
\hline & Myocardial infarction & 1 epidural) & 3 & - & - \\
\hline & Ventricular tachycardic & & 1 & - & - \\
\hline & Supraventricular tachy & spinal, 1 ophthalmic) & 1 & - & 1 \\
\hline & Arrhythmia (1 brachia & & - & 1 & - \\
\hline & Left ventricular failure & almic) & - & - & 2 \\
\hline D & Drugs (22 cases) & & & & \\
\hline & Wrong drug & Syringe swap & 5 & - & - \\
\hline & & Wrong local anaesthetic & 2 & - & - \\
\hline & Wrong concentration & & 6 & - & - \\
\hline & Drug not given & & 2 & - & - \\
\hline & Communication problem & $\begin{array}{l}\text { Communication about } \\
\text { subcutaneous heparin }\end{array}$ & 1 & - & - \\
\hline & & $\begin{array}{l}\text { Communication about } \\
\text { intrathecal morphine }\end{array}$ & 1 & - & - \\
\hline & Wrong route & Inadvertent epidural metaraminol & 2 & - & - \\
\hline & & Inadvertent epidural ranitidine & 1 & - & - \\
\hline & & $\begin{array}{l}\text { Epidural infusion connected to } \\
\text { intravenous infusion }\end{array}$ & 2 & - & - \\
\hline
\end{tabular}

Total sample included *E/S, epidural or spinal block cases (98 epidural, 91 spinal, 4 combined, 3 caudal); $† \mathrm{BrPl}$, brachial plexus block cases ( 12 axillary block, 5 interscalene block, 3 supraclavicular block, 1 not stated); $¥$ Oph, ophthalmic block cases ( 9 peribulbar, 9 retrobulbar, 5 not stated). 
its putative effectiveness was tested against the reports. How this was done is described elsewhere in this set of articles. ${ }^{9}$ The potential value of this structured approach (that is, the application of $\mathrm{AB}$ COVER CD-A SWIFT CHECK to the diagnosis and initial management of the problem, followed by the application of the regional anaesthesia sub-algorithm) was assessed in the light of AIMS reports by gauging its potential effectiveness for each reported incident.

\section{RESULTS}

Of the first 4000 AIMS reports, there were 252 cases for which regional anaesthesia was the anaesthetic technique. Epidurals (including caudal blocks) and spinals accounted for 196 cases $(78 \%)$. There were 23 ophthalmic blocks $(9 \%)$, 21 brachial plexus blocks ( $8 \%$ ), eight local nerve blocks (3\%), and five Biers blocks (2\%). The regional anaesthesia techniques used are shown in table 1, table 2 the surgical specialty type, table 3 the ASA status of the patients, table 4 the timing of the event, and table 5 shows the physiological outcome.

Classifications of the epidural/spinal group, the brachial plexus block group, and the ophthalmic block group, according to the application of the algorithms, are shown in tables 6 and 7 .
In the epidural/spinal events the use of the core algorithm AB COVER CD-A SWIFT CHECK would have predicted or diagnosed adverse events in $95(48 \%)$ of the 196 incidents in this group (table 6) or $143(73 \%)$ if local anaesthesia drug problems are included.

Hypotension and dysrhythmias were the most significant, commonly occurring problems, comprising 50 (26\%) of the 196 epidural/spinal problems. Drug related events constituted the next most important category in the COVER algorithm (table 6 ), and accounted for 22 (11\%) of regional anaesthesia incidents associated with epidural or spinal anaesthesia, or $70(36 \%)$ if local anaesthetic drug problems are included.

The algorithm, AB COVER CD-A SWIFT CHECK, correctly applied to the 252 reports for regional anaesthesia, would have predicted or diagnosed adverse events in $45 \%$ of cases; the remaining $55 \%$ would have been picked up by the specific sub-algorithm for regional anaesthesia.

\section{DISCUSSION}

It is important that the generic core algorithm $A B$ COVER CD-A SWIFT CHECK be run through rapidly early on, so that unusual but potentially dangerous problems unrelated to the regional anaesthesia itself are detected and managed (for example, a problem with oxygen delivery, a vaporiser

Table 7 Regional anaesthesia sub-algorithm

\begin{tabular}{|c|c|c|c|c|}
\hline \multirow[b]{2}{*}{ Classification } & \multirow[b]{2}{*}{ Description } & \multicolumn{3}{|c|}{ Number } \\
\hline & & $E / S^{*}$ & BrPlt & Oph‡ \\
\hline \multirow[t]{3}{*}{ Ask the patient ( 6 cases) } & Wrong patient & 1 & - & - \\
\hline & Wrong side & - & 2 & 2 \\
\hline & Failed block & - & - & 1 \\
\hline \multirow{3}{*}{$\begin{array}{l}\text { Local anaesthetic toxicity } \\
\text { (11 cases) }\end{array}$} & Fitting & 2 & & - \\
\hline & Nausea & 1 & - & - \\
\hline & Other effects & 8 & & \\
\hline \multirow[t]{7}{*}{ Assess level of block ( 30 cases) } & Overdose, $n=20$ & & & 3 \\
\hline & Total spinal & 14 & - & - \\
\hline & High block/prolonged recovery & 3 & - & - \\
\hline & Underdose/failed block, $\mathrm{n}=10$ & & & \\
\hline & Incorrect infusion rate & 3 & - & - \\
\hline & Communication error & 1 & - & - \\
\hline & Not stated & 6 & - & - \\
\hline \multicolumn{5}{|c|}{ Catheter/needle problems (76 cases) } \\
\hline \multirow{2}{*}{\multicolumn{5}{|c|}{$\begin{array}{l}\text { Inadvertent intravascular placement or injection (20 cases) } \\
\text { Fitting (5 brachial plexus blocks) }\end{array}$}} \\
\hline & & & & \\
\hline & & & & \\
\hline \multicolumn{5}{|c|}{ Inadvertent intrathecal placement or injection (35 cases) } \\
\hline & Inadvertent subarachnoid injection & 1 & - & - \\
\hline & $\begin{array}{l}\text { Dural puncture (17 with headaches; } \\
10 \text { without headache; } 6 \text { not stated) }\end{array}$ & 33 & - & - \\
\hline & Migration of epidural catheter & 1 & - & - \\
\hline \multicolumn{5}{|c|}{ Inadvertent subdural placement or injection ( 3 cases) } \\
\hline & Subdural drug effect & 3 & - & - \\
\hline \multicolumn{2}{|c|}{ Blocked/kinked/split catheter, or catheter pulled out (4 cases) } & 4 & - & - \\
\hline \multirow[t]{5}{*}{ Trauma (7 cases) } & Pneumothorax & - & 1 & - \\
\hline & Epidural haematoma & 1 & - & - \\
\hline & Bloody spinal tap & 2 & - & - \\
\hline & $\begin{array}{l}\text { Haematoma/haemorrhage after } \\
\text { ophthalmic block }\end{array}$ & - & - & 2 \\
\hline & Corneal damage & - & - & 1 \\
\hline \multirow[t]{2}{*}{ Infection ( 2 cases) } & Epidural abscess & 1 & - & - \\
\hline & Positive catheter tip culture & 1 & - & - \\
\hline \multirow[t]{2}{*}{ Pain (5 cases) } & $\begin{array}{l}\text { Dural puncture headache after spinal } \\
\text { block§ }\end{array}$ & 4 & - & - \\
\hline & Backache after epidural block & 1 & _ & _- \\
\hline $\begin{array}{l}\text { Consequences of sensory/ } \\
\text { motor blockade (1 case) }\end{array}$ & Fall post-spinal block & 1 & - & - \\
\hline Miscellaneous & Hypothermia after epidural block & 2 & - & - \\
\hline Remaining (6 cases) & Other & - & - & 4 \\
\hline \multicolumn{5}{|c|}{$\begin{array}{l}\text { Total sample included *E/S, epidural or spinal block cases ( } 98 \text { epidural, } 91 \text { spinal, } 4 \text { combined, } 3 \text { caudal) } ; \uparrow \mathrm{BrPl} \text {, } \\
\text { brachial plexus block cases ( } 12 \text { axillary block, } 5 \text { interscalene block, } 3 \text { supraclavicular block, } 1 \text { not stated); } \neq \text { Oph, } \\
\text { ophthalmic block cases ( } 9 \text { peribulbar, } 9 \text { retrobulbar, } 5 \text { not stated). } \\
\text { \$A total of } 16 \text { blood patches were required after dural puncture. }\end{array}$} \\
\hline
\end{tabular}


inadvertently left on), as these may easily be missed if the anaesthetist is focussed on problems specifically related to the regional anaesthetic technique itself. It is also of note that over half $(59 \%)$ of all the incidents occurred in patients of ASA grades 1 or 2 (table 3 ).

Hypotension and dysrhythmias were the most significant, commonly occurring problems, comprising $26 \%$ of the epidural/spinal problems. These occurred soon after insertion of the block or during the maintenance phase (see table 4) and were responsible for all six deaths in the 252 regional anaesthesia incidents. The importance of vigilance for hypotension and a prompt, appropriate response during epidural and spinal anaesthesia cannot be overemphasised. Underestimated hypovolaemia or blood loss (for example, a haematoma in association with a fractured hip), relative overdose of local anaesthetic agent, or inadvertent subarachnoid injection with an epidural (especially in elderly, frail patients) may all set the stage for a fatal outcome. Addressing cardiovascular problems thus has high priority in the regional anaesthesia sub-algorithm (see fig l).

There were three major subtypes of drug related events: the wrong concentration, the wrong drug, and the wrong route, all approximately equally represented. Absolute or relative overdose resulting in local anaesthetic toxicity and catheter problems with delivery of local anaesthetic drugs to their site of action are considered under the regional anaesthesia subalgorithm, and accounted for an additional 49 (25\%) of the epidural/spinal cases. In four cases of incorrect concentration, a simple dilutional error was made.

In two cases, the local anaesthetic intended for skin infiltration was mistakenly used for the block. Drug swaps included ephedrine for adrenaline, thiopentone for omnopon, vecuronium for verapamil, and suxamethonium for an antibiotic. The wrong route of administration problems included: local anaesthetic intended only for infiltration being injected intravenously in seven cases (table 7); the intravenous drugs ranitidine and metaraminol being injected epidurally in three cases, and a test dose of local anaesthetic being injected into the subarachnoid rather than the epidural space. The recognition of drug related incidents depends on adherence to good protocols and a high level of awareness by the anaesthetist.

Problems specifically associated with the regional anaesthetic technique accounted for 101 (52\%) of the 196 epidural/ spinal incidents. Inadvertent subarachnoid or subdural injection or puncture made up 38 cases, problems with the level or efficiency of the block 27 cases, local anaesthetic toxicity 11 cases, and trauma, infection, or pain from the needle or catheter made up a further 10 cases. The relative importance of these problems is reflected in the sequence of actions recommended in the sub-algorithm on regional anaesthesia (see fig 1 ).

There were 20 events associated with brachial plexus blockade. Seventeen $(81 \%$ of them) would have been identified using the $\mathrm{AB}$ COVER $\mathrm{CD}$ algorithm if local anaesthetic drug problems are included under D. The most common critical incident in this brachial plexus group was intravascular injection of local anaesthetic, sometimes despite careful attempts by the anaesthetist to exclude this possibility during injection. Thirteen such events were described, producing various effects, including fitting in five cases (table 7). Blockade of the incorrect limb occurred in two cases.

There were 23 events in the ophthalmic group; 10 of these would have been identified using the $A B$ COVER $C D$ algorithm. Bradycardia accounted for five cases. The importance of sustained vigilance throughout the procedure cannot be overstated as one patient fell off the table and another sustained corneal damage due to inappropriate application of

\section{Key messages}

- Of the first 4000 AIMS reports, there were 252 cases involving regional anaesthesia; of these, $78 \%$ involved epidural or spinal anaesthesia, $9 \%$ were ophththalmic blocks, $8 \%$ were brachial plexus blocks, $3 \%$ were local nerve blocks, and $2 \%$ were Biers blocks.

- The incidents occurred across 11 types of surgical specialty, the most common of which were obstetrics $(26 \%)$, orthopaedics $(18 \%)$, urology $(16 \%)$, vascular surgery (12\%), and general surgery (11\%).

- The vast majority of patients (92\%) were ASA grades I to III.

- Most incidents (82\%) occurred during establishment of the block or during maintenance of anaesthesia.

- Major physiological change occurred in $38 \%$ of the cases and death occurred in another six patients.

- The most significant of the commonly occurring clinical problems in this series were hypotension and cardiac dysrhythmias (comprising $26 \%$ of the epidural/spinal cases and responsible for all six deaths in this series).

- In the COVER algorithm step, drug related events were the most important category $(36 \%)$ equally divided between wrong concentration, wrong drug, and wrong route.

- In the regional anaesthesia sub-algorithm step the most frequently reported category was inadvertent "intrathecal placement or injection" (27\%).

- The most common critical incident among the 20 brachial plexus incidents was intravascular injection of the local anaesthetic.

- In two ophthalmic blocks the wrong side was blocked.

- The algorithm AB COVER CD-A SWIFT CHECK correctly applied would have diagnosed $45 \%$ of cases. The specific sub-algorithm for regional anaesthesia would have identified the remaining $55 \%$.

- This series again reveals the dangerous misconception that an anaesthesia procedure is safe "... because it is only a regional block"!

the mercury weight following peribulbar injection. In two cases the incorrect side was blocked; in both of these cases the patient identified the incorrect side as correct for operation, although each written consent form identified the correct side. It is therefore essential, when checking the operative side, that both the patient and the related consent form be consulted.

The remaining groups include Bier's blocks, cervical plexus blocks, and a small group of miscellaneous blocks. There were five events associated with Bier's blocks. Four of these involved tourniquet failure; in the fifth, the patient sustained a convulsion while moving across to the bed following completion of the procedure, 30 minutes after the dose of local anaesthetic. As has been emphasised elsewhere, beware the assistant who releases the tourniquet inadvertently.

There were three events associated with cervical plexus blocks (table 1). One incident involved an intravascular injection with a convulsion, the second a wrong drug chosen but not given due to a pre-administration check, and the third involved undetected hypotension during carotid endarterectomy, in which the anaesthetist had given the one available invasive monitoring transducer to the surgeon. 
There were five events not easily classified. Of significance among these was the development of hypoxia associated with kinking of the oxygen tubing from the common gas outlet to the Hudson mask; this underlines the importance of always going through the core COVER algorithm.

In summary, the core algorithm $\mathrm{AB}$ COVER $\mathrm{CD}$ properly applied, would have accounted for $45 \%$ of all problems, and is worth going through to eliminate unexpected problems unrelated to the regional anaesthesia technique itself. Hypotension and dysrhythmias occurred in over 30\% of all incidents and accounted for all six deaths. The specific subalgorithm for regional anaesthetic techniques accounted for $55 \%$ of all incidents: problems with delivery to the site of action, 49 cases (19\%); problems with the block, 30 cases (12\%); local anaesthetic toxicity, 30 cases (12\%); trauma, infection or pain, 14 cases $(6 \%)$, wrong side or wrong patient, five cases $(2 \%)$.

Finally, it is important that a full explanation of what happened be given to the patient, that the event and the results of any tests are documented in the anaesthetic record, and, if appropriate, that the patient be given a letter to warn future anaesthetists. If a particular precipitating event was significant, or a particular action was useful in resolving the crisis, this should be clearly explained and documented.

\section{ACKNOWLEDGEMENTS}

The authors would like to thank all the anaesthetists in Australia and New Zealand who contributed to the 4000 incident reports upon which this and the other 24 papers in the Crisis Management Series are based. The coordinators of the project also thank Liz Brown for preparing the draft of the original Crisis Management Manual; Loretta Smyth for typing; Monika Bullock, RN, for earlier coding and classifying of data; Dr Charles Bradfield for the electronic version of the algorithms; Dr Klee Benveniste for literature research; Drs Klee Benveniste, Michal Kluger, John Williamson, and Andrew Paix for editing and checking manuscripts.
Authors' affiliation

M A L Fox, Senior Staff Specialist, Department of Anaesthesia and Intensive Care, Royal Adelaide Hospital and University of Adelaide, Adelaide, South Australia, Australia

R W Morris, Senior Staff Specialist and Director, Sydney Medical Simulation Centre, Royal North Shore Hospital, St Leonards, New South Wales, Australia

W B Runciman, Professor and Head, Department of Anaesthesia and Intensive Care, University of Adelaide and Royal Adelaide Hospital, Adelaide, South Australia, Australia

A D Paix, Consultant Anaesthetist, Princess Royal University Hospital, Orpington, Kent, UK

This study was coordinated by the Australian Patient Safety Foundation, GPO Box 400, Adelaide, South Australia, 5001, Australia.

\section{REFERENCES}

1 Cox B, Durieux ME, Marcus MA. Toxicity of local anaesthetics. Best Prac Res Clin Anaesthesiol 2003;17:111-36.

2 Klein SM, Pierce T, Rubin Y, et al. Successful resuscitation after ropivacaineinduced ventricular fibrillation. Anesth Analg 2003;97:901-3.

3 Fox MAL, Webb RK, Singleton RJ, et al. Problems with regional anaesthesia: an analysis of 2000 incident reports. Anaesth Intensive Care 1993;21:646-9

4 Ben-David B. Complications of regional anesthesia: an overview. Anesthesiol Clin North America 2002;20:665-7, ix.

5 De Tommaso O, Caporuscio A, Tagariello V. Neurological complications following central neuraxial blocks: are there predictive factors? Eur J Anaesthesiol 2002;19:705-16.

6 Runciman WB, Webb RK, Klepper ID, et al. Crisis management: validation of an algorithm by analysis of 2000 incident reports. Anaesth Intensive Care 1993;21:579-92.

7 Webb RK, Currie M, Morgan CA, et al. The Australian Incident Monitoring Study: an analysis of 2000 incident reports. Anaesth Intensive Care 1993;21:520-8.

8 Webb RK, van der Walt JH, Runciman WB, et al. Which monitor? An analysis of 2000 incident reports. Anaesth Intensive Care 1993;21:529-42

9 Runciman WB, Kluger MT, Morris RW, et al. Crisis management during anaesthesia: the development of an anaesthetic crisis management manual. Qual Saf Health Care 2005; 14:el.

10 Australian Patient Safety Foundation. Crisis Management Manual: COVER $A B C D$ A SWIFT CHECK. Adelaide: Australian Patient Safety Foundation, 1996:74. Available at hitp://www. apsf.net.au/anaesthesia.htm (accessed 6 September 2004) 